\title{
Photoluminescence of monoclinic $\mathrm{Li}_{3} \mathrm{AlF}_{6}$ crystals under vacuum ultraviolet and soft $\mathrm{X}$-ray excitations
}

\author{
V.A. Pustovarov ${ }^{\mathrm{a}}$, I.N. Ogorodnikov ${ }^{\mathrm{a}}$, S.I. Omelkov, ${ }^{\mathrm{b}, *}$, M.S. Molokeev ${ }^{\mathrm{c}, \mathrm{d}}$, \\ A.V. Kozlov ${ }^{\text {a }}$ L.I. Isaenko ${ }^{\mathrm{e}, \mathrm{f}}$ \\ ${ }^{a}$ Ural Federal University, 19, Mira Street, 620002 Yekaterinburg, Russia \\ ${ }^{b}$ Institute of Physics, University of Tartu, 14c, Ravila Street, 50411 Tartu, Estonia \\ ${ }^{c}$ Kirensky Institute of Physics SB RAS, Akademgorodok 50, 660036 Krasnoyarsk, Russia \\ ${ }^{d}$ Far Eastern State Transport University, 47, Serysheva Street, 680021 Khabarovsk, Russia \\ ${ }^{e}$ Institute of Geology and Mineralogy SB RAS, 43, Russkaya Street, 630058 Novosibirsk, Russia \\ ${ }^{f}$ Novosibirsk National Research University, 2, Pirogova Street, 630090 Novosibirsk, Russia
}

\begin{abstract}
Using Bridgman technique we have grown monoclinic $\beta$-LiAF crystals suitable for optical studies, performed XRD-identification and Rietveld refinement of the crystal structure and carried out a photoluminescence study upon vacuum ultraviolet (VUV) and extreme ultraviolet (XUV)-excitations, using the low-temperature $(T=7.2 \mathrm{~K})$ time-resolved VUV-spectroscopy technique. The intrinsic PL emission band at $340-350 \mathrm{~nm}$ has been identified as due to radiative recombination of self-trapped excitons. The electronic structure parameters were determined: bandgap $E_{\mathrm{g}} \approx 12.5 \mathrm{eV}$, energy threshold for creation of unrelaxed excitons $11.8 \mathrm{eV}<E_{\mathrm{n}}<12.5 \mathrm{eV}$. The PL emission bands at 320-325 and $450 \mathrm{~nm}$ were attributed to luminescence caused by lattice defects. We have discovered an efficient excitation of PL emission bands in the energy range of interband transitions $\left(E_{\mathrm{ex}}>13.5 \mathrm{eV}\right)$, as well as in the energy range of core transitions at $130 \mathrm{eV}$. We have revealed UV-VUV PL emission bands at 170 and $208 \mathrm{~nm}$ due to defects. A reasonable assumptions about the origin of the UV-VUV bands were discussed.

Keywords:

$\mathrm{Li}_{3} \mathrm{AlF}_{6}$, Time-resolved luminescence, VUV spectroscopy, Defects
\end{abstract}

${ }^{*}$ Corresponding author. Tel.: +372 7374787

Email address: omelkovs@gmail .com (S.I. Omelkov) 


\section{Introduction}

Owing to a large energy bandgap, complex fluorides have many practical applications. However, Lithium Hexafluoroaluminate $\mathrm{Li}_{3} \mathrm{AlF}_{6}$ (LiAF) crystals are practically unknown as optical materials. LiAF is utilized as a water insoluble Aluminum source for use in oxygen-sensitive applications, such as metal production. In extremely low concentrations ( $\mathrm{ppm}$ ), fluoride compounds are used in health applications.

LiAF crystals exist in two basic modifications. $\alpha$-LiAF modification can be obtained by quenching a corresponding sample from temperatures above $600^{\circ} \mathrm{C}$ to room temperature. The $\alpha$-LiAF crystal structure has been determined at room temperature in Ref. [1], and it possesses an orthorhombic Pna2 ${ }_{1}$ symmetry with lattice constants of $a=9.510, b=8.2295, c=4.8762 \AA$. Each of the ten atoms in formula unit occupies fourfold-coordinated site. Almost regular $\mathrm{AlF}_{6}$ octahedra are linked with Li ions, each of which has six neighboring $\mathrm{F}$ ions at a distance of 1.87-2.42 $\AA$. Bond length $\mathrm{Al}-\mathrm{F}$ is about $1.786-1.830 \AA$. While the pseudoface-centered cubic array of $\mathrm{AlF}_{6}$ octahedra in $\alpha$-LiAF looks similar to that of the mineral cryolite, its deviations from the ideal structure of cryolite are quite significant. LiAF transformation into an ideal cryolite structure can only occur at elevated temperature. Several polymorphic transformations were revealed in the temperature range between room temperature and its melting point $\left(T_{\text {melt }}=783^{\circ}\right)$ $[2,3]$.

$\beta$-LiAF modification crystallizes only during slow cooling, it is isotypic to $\beta$ $\mathrm{Li}_{3} \mathrm{VF}_{6}$, and possesses monoclinic $C 2 / c$ symmetry with $a=14.201(1), b=8.387(1)$, $c=9.860(1) \AA$, and $\beta=94.07(1)^{\circ}$ [4]. Only a few research works have been devoted to the study of $\beta$-LiAF: among them, thermodynamic analysis of lithium cryolite in the $\mathrm{LiAF}-A \mathrm{~F}_{2}(A=\mathrm{Ca}, \mathrm{Ba}, \mathrm{Sr})$ systems [5]; study of the heat capacity of $\beta$ LiAF in the temperature range from 15 to $380 \mathrm{~K}$ [6]; electrical conductivity of low melting baths for aluminium electrolysis: the system $\mathrm{Na}_{3} \mathrm{AlF}_{6}-\mathrm{LiAF}-\mathrm{AlF}_{3}$ [7]; $\mathrm{Li}^{+}$-ion conductivity of LiAF [8].

We are not aware of any research work on optical and luminescence properties of $\mathrm{LiAF}$, whereas related $\mathrm{Li} M \mathrm{AlF}_{6}(M=\mathrm{Ba}, \mathrm{Ca}, \mathrm{Sr})$ single crystals are much better studied in this regard. This applies not only to study of the crystal structure [9], but also to study of the luminescence and optical properties of both the undoped crystals [10-12], and crystals doped with $\mathrm{Ce}^{3+}[13,14], \mathrm{Cr}^{3+}$ [15], and $\operatorname{Pr}^{3+}$ [16]. Electronic properties of undoped $\mathrm{Li} M \mathrm{AlF}_{6}$ crystals have been studied experimentally using vacuum ultraviolet optical and luminescence spectroscopy $[12,17]$, and X-ray photoelectron spectroscopy techniques [17]. Ab initio electronic struc- 
ture calculations have been done for $\mathrm{LiCaAlF}_{6}$ (LICAF) single crystals $[18,19]$. The other related crystals of $\mathrm{LiBaF}_{3}$ are known as window materials in the ultraviolet (UV) and vacuum ultraviolet (VUV) wavelength regions [20], as well as a scintillator for thermal-neutron detection with optimal $n / \gamma$ discrimination [21].

The aim of this research work is to study luminescence and optical properties of undoped LiAF crystals using the method of low-temperature time-resolved luminescence spectroscopy upon selective photoexcitation by VUV synchrotron radiation. LiAF crystals were grown by the Bridgman method, XRD-analysis and Rietveld refinement were carried out to identify and clarify the crystal structure. Analysis of the experimental spectroscopy results is performed with consideration of known data on related crystals.

\section{Experimental details}

\subsection{Time-resolved PL spectroscopy}

The present study was carried out using three different experimental setups. Let us briefly describe the relevant parameters of these facilities.

The low-temperature luminescence spectroscopy in UV-VUV spectral range with the time resolution upon selective excitation in the soft X-ray (XUV) energy range was carried out using synchrotron radiation (SR) at BW3 channel (HASYLAB, DESY, Hamburg). SR pulses from the undulator was monochromatized by a Zeiss SX700 monochromator. Time-resolved photoluminescence (PL) emission spectra in the VIS-UV-VUV regions $(140-500 \mathrm{~nm})$ as well as PL decay kinetics curves were recorded using a $0.4 \mathrm{~m}$ vacuum monochromator (Seya-Namioka scheme) equipped with a microchannel plate-photomultiplier (MCP1645 Hamamatsu) [22]. The spectra were recorded in two independent time windows (TWs) set for detection of luminescence signal within 1.2-9.5 ns $\left(\mathrm{TW}_{1}\right)$ and 19-90 ns $\left(\mathrm{TW}_{2}\right)$ relative to the beginning of the SR pulse. The effective time resolution of the entire detection system was 250 ps. Time-integrated (TI) spectra were recorded within the full time range available between two sequential excitation pulses, viz. $192 \mathrm{~ns}$. The measurements were performed in the ultra-high-vacuum chamber (up to $10^{-9}$ mbar) at $T=7-8 \mathrm{~K}$.

PL emission spectra, PL decay kinetics, and time-resolved PL excitation (PLE) spectra were recorded upon selective VUV-excitation at SUPERLUMI station (Channel I, HASYLAB, DESY, Hamburg) [23] using an ARC Spectra Pro-308i monochromator and cooled CCD camera. The PLE spectra were recorded in two independent TWs set for detection of luminescence signal within 0.6-2.9 ns $\left(\mathrm{TW}_{1}\right)$ and $58-72 \mathrm{~ns}\left(\mathrm{TW}_{2}\right)$ relative to the beginning of the SR pulse. The time 
resolution of the entire detection system was $1 \mathrm{~ns}$ (FWHM). The full time range available between two sequential excitation pulses was $96 \mathrm{~ns}$. The PL emission spectra were corrected to spectral sensitivity of the registration system.

In addition, PL emission spectra in the UV-VUV energy region were recorded upon VUV-excitation (6-12 eV) using the mobile luminescence set-up [22] attached to the branch-line FINEST of I3 beamline at MAX-lab, Lund [24]. The detection system is identical to the one used in XUV experiment at BW3 beamline. All the PL excitation spectra presented in this paper were corrected to an equal number of photons incident on the sample using sodium salicylate.

\subsection{Samples preparation and XRD analysis}

$\mathrm{Li}_{3} \mathrm{AlF}_{6}$ compound was obtained from $\mathrm{LiF}$ and $\mathrm{AlF}_{3}$ powders $(99,5 \%)$, which were annealed in vacuum at $200^{\circ} \mathrm{C}$ during 5 hours before weighting. A glassgraphite crucible with a conic bottom was filled with the stoichiometric mixture of $\mathrm{LiF}$ and $\mathrm{AlF}_{3}$ and placed into evacuated and hermetically sealed silica ampoule. The synthesis took place in a hot zone of Bridgman furnace at $900^{\circ} \mathrm{C}$ during 1 hour. When synthesis was finished, the ampoule was being moved from hot zone to warm one with a temperature of $600^{\circ} \mathrm{C}$ with the rate of $0.5 \mathrm{~mm} / \mathrm{h}$. Thus polycrystalline boules of $\mathrm{Li}_{3} \mathrm{AlF}_{6}$ with grains up to $5 \times 5 \times 5 \mathrm{~mm}^{3}$ in size were obtained.

The powder diffraction data of $\mathrm{Li}_{3} \mathrm{AlF}_{6}$ for Rietveld analysis were collected at room temperature using a Bruker D8 ADVANCE powder diffractometer $(\mathrm{Cu}-$ $\mathrm{K}_{\alpha}$ radiation) and linear VANTEC detector. The step size of $2 \Theta$ was $0.016^{\circ}$, and the counting time was $1 \mathrm{~s}$ per step. Rietveld refinement was performed using TOPAS 4.2 [25]. Almost all peaks were indexed by monoclinic cell (C2/c) with parameters close to previously published $\beta-\mathrm{Li}_{3} \mathrm{AlF}_{6}$ [4]. Two peaks at $2 \Theta \approx 20^{\circ}$ and $2 \Theta \approx 26^{\circ}$ could not be attributed to the main phase. Unfortunately, these two peaks do not give enough information for phase identification of impurity, but rough estimation of its fraction using intensities gave $<3 \%$. Therefore the crystal structure [4] was taken as starting model for the Rietveld refinement. Refinement was stable and gives quite low $R$-factors, Tab. 1 , Fig. 1 . Coordinates of atoms and main bond lengths are listed in Tab. 2 and Tab. 3 respectively. Bond lengths Al-F are in usual range $1.772(9)-1.862(8) \AA, \mathrm{Li}-\mathrm{F}$ bond lengths span the wide range 1.66(3)-2.55(3) $\AA$, and this is common situation for this compound [4]. Primitive unit cell contains two independent $\mathrm{Al}$ ions which form $\mathrm{AlF}_{6}$ octahedra, five $\mathrm{Li}$ ions which form three $\mathrm{LiF}_{6}$ octahedra, one $\mathrm{LiF}_{5}$ tetragonal pyramid and one $\mathrm{LiF}_{4}$ tetrahedron, Fig. 2. Each $\mathrm{AlF}_{6}$ octahedra linked with $\mathrm{LiF}_{n}$ polyhedra by nodes or edges with common $\mathrm{F}$ ions and, in summary, all polyhedra form $3 D$ network. 


\section{Time-resolved luminescence spectroscopy}

\subsection{Vacuum ultraviolet excitation}

Figure 3 shows PL emission spectra of LiAF crystals recorded at $T=7.2 \mathrm{~K}$ upon VUV-excitation at different energies $E_{\mathrm{ex}}$ ranging from 6.20 to $13.80 \mathrm{eV}$. The spectra comprised of several broad PL emission bands with maxima at 320-350 and $450 \mathrm{~nm}$, and their relative intensities depend on the excitation energies $E_{\mathrm{ex}}$. At $E_{\mathrm{ex}}=6.20$ and $6.80 \mathrm{eV}$, PL emission bands peaking at 320-325 and $450 \mathrm{~nm}$ are almost comparable in intensity. At $E_{\mathrm{ex}}=9.48 \mathrm{eV}$, the emission intensity is reduced by a factor of about $4-5$, but there is only one broad PL emission band peaking at $340 \mathrm{~nm}$. With further increase in $E_{\mathrm{ex}}$, there is only one broad PL emission band peaking at $340-350 \mathrm{~nm}$. It is worth noting that this PL emission band is the most intense one recorded upon excitation at $E_{\mathrm{ex}}=11.8 \mathrm{eV}$ and $E_{\mathrm{ex}}>13.5 \mathrm{eV}$.

Figure 4 shows PLE spectra of LiAF crystals recorded at $T=7.2 \mathrm{~K}$ monitoring emissions at 440 and $340 \mathrm{~nm}$ in either time-integrated regime (TI) or within time-windows $\mathrm{TW}_{1}$ and $\mathrm{TW}_{2}$. Time-integrated PLE spectrum recorded monitoring emission at $\lambda_{\mathrm{m}}=440 \mathrm{~nm}$ comprises a low-intensity emission band at $6.14 \mathrm{eV}$, the dominant peak at $11.8 \mathrm{eV}$, deep minimum in the energy range of about $12.8 \mathrm{eV}$ and, finally, the rise of the intensity in the energy region of $E_{\mathrm{ex}}>13.5 \mathrm{eV}$. When changing $\lambda_{\mathrm{m}}$ to $340 \mathrm{~nm}$, PLE(TI) spectrum remains qualitatively the same, but the intensity ratio for the PL emission bands varies, Fig. 4. In the energy range of $E_{\mathrm{ex}}>13.5 \mathrm{eV}$, PLE intensity increases, whereas the intensity of the $6.14 \mathrm{eV}$ PLE-band decreases by a factor of about three. The time-resolved spectra $\mathrm{TW}_{1}$ and $\mathrm{TW}_{2}$ indicate that the PL decay kinetics should include nanosecond decay components with different lifetimes.

Figure 5 shows PL decay kinetics of LiAF crystals recorded at $T=7.2 \mathrm{~K}$ monitoring emissions at $\lambda_{\mathrm{m}}=440$ and $340 \mathrm{~nm}$ upon VUV-excitations at different energies $E_{\text {ex }}$. From Fig. 5 it follows that PL decay kinetics is different for each of the PL emission bands and it depends also on $E_{\text {ex }}$. The experimental equipment did not allowed us to measure the PL decay components with lifetimes of the microsecond time-range. Such long decaying components were apparent in our measurements in the form of a constant level — pedestal. Such a way, PL decay kinetics recorded at $\lambda_{\mathrm{m}}=340 \mathrm{~nm}, E_{\mathrm{ex}}=6.2-6.8 \mathrm{eV}$, is dominated by a fast nanosecond $(\tau=3.2 \mathrm{~ns})$ component with contribution of $90-97 \%$ that manifests itself on the pedestal of the slow decaying component with lifetime of microsecond timerange. At $E_{\mathrm{ex}}>11.8 \mathrm{eV}$, the pedestal dominates with the contribution of $65-75 \%$, whereas the contribution of the fast component $(\tau=9.6 \mathrm{~ns})$ decreased accordingly. Qualitatively similar picture is observed for PL decay kinetics recorded 
at $\lambda_{\mathrm{m}}=440 \mathrm{~nm}$. However, the pedestal contributes $50 \%$ even at $E_{\mathrm{ex}}=6.2 \mathrm{eV}$. At the further increase in energy $E_{\text {ex }}$ to $10.78 \mathrm{eV}$, the contribution of the nanosecond component ( $\tau=10.2 \mathrm{~ns}$ ) remains practically unchanged.

Figure 6 shows time-resolved PL emission spectra of LiAF crystals recorded at $T=300 \mathrm{~K}$ monitoring emission within time-window 1-6 ns using SR-excitation pulses with the $10 \mathrm{~ns}$ repetition period. The PL emission spectra are recorded in a wide UV-VUV spectral range upon VUV-excitation at different energies $E_{\text {ex }}$. To exclude the contribution of the scattered light, the PL emission spectra were recorded monitoring emission within time window of 1-6ns, which means the $5 \mathrm{~ns}$-wide time-window delayed by $1 \mathrm{~ns}$ relative to the arrival of SR-excitation pulses. It is quite clear that the long-wavelength emission bands at $\lambda_{\mathrm{m}}>300 \mathrm{~nm}$ do not show significant intensity in the PL emission spectrum. Therefore, the photoluminescence yield for long-wavelength emission bands at room temperature undergoes thermal quenching. At the same time, it was revealed that VUV-UV luminescence yield decreases with decreasing temperature. However, a study of the temperature dependence of the PL emission of LiAF crystals in a wide spectral range is not a subject of this research work. The most important result follows from Fig. 6: there are two intense VUV-UV emission bands at $170 \mathrm{~nm}(7.28 \mathrm{eV})$ and $208 \mathrm{~nm}(5.96 \mathrm{eV})$, which dominate the PL emission spectrum at $300 \mathrm{~K}$.

Figure 7 shows PLE-spectra of LiAF crystals recorded at $T=300 \mathrm{~K}$ monitoring emissions in the UV-VUV energy range. The PLE spectrum recorded monitoring emission at $\lambda_{\mathrm{m}}=208 \mathrm{~nm}$ (UV-emission band) comprises three PLE bands at 8.02, 8.7 and $10.5 \mathrm{eV}$, Fig. 7 (plot 2). When $\lambda_{\mathrm{m}}$ is changed to $170 \mathrm{~nm}$, only two PLEbands at 8.02 and $8.7 \mathrm{eV}$ remain. An increase in energy $E_{\mathrm{ex}}$ above $9 \mathrm{eV}$ leads to a sharp drop in the PL output (Fig. 7, plot 1). Therefore the PLE-spectra of VUV bands (Fig. 7) differ considerably from PLE-spectra for long-wavelength bands at 450 and $320-340$ nm, Fig. 4.

\subsection{Soft $X$-ray excitation}

Figure 8 shows PL emission spectra of LiAF crystals recorded at $T=300 \mathrm{~K}$ monitoring emission in time-integrated mode (TI), and within time-windows $\mathrm{TW}_{1}$ and $\mathrm{TW}_{2}$ upon XUV excitation at $E_{\mathrm{ex}}=130 \mathrm{eV}$. The PL emission spectra were recorded in a wide VUV-UV-Vis spectral region and they cover both the longwavelength bands at 320-325 and $450 \mathrm{~nm}$, and the UV-VUV bands I and II. At a qualitative level, the PL emission spectra registered upon soft X-ray excitation

perfectly correlate with the above results obtained by VUV excitation. We observe the same relatively narrow bands at 170 (I) and $208 \mathrm{~nm}$ (II) in the VUV-UV spectral region and the broader long-wavelength bands at 320 and $440 \mathrm{~nm}$. However, 
the relative intensities of the PL emission bands recorded upon VUV- and XUVexcitations are different that naturally should be associated with such methods of PL excitations: intracenter (VUV) and recombination (XUV) PLE-mechanisms.

Figure 9 shows PL decay kinetics of LiAF crystals recorded at $T=300 \mathrm{~K}$ monitoring emissions at $\lambda_{\mathrm{m}}=440$ and $320 \mathrm{~nm}$ upon XUV-excitations at $E_{\mathrm{ex}}=130 \mathrm{~nm}$. It is worth noting that the VUV-UV emission bands exhibit mainly a pedestal slowly decaying components with lifetimes in the micro- and possibly millisecond time-range. From Fig. 9 it follows that the PL decay kinetics of the longwavelength emission band comprises a fast nanosecond component with lifetime $\tau=3.8 \mathrm{~ns}$, which contributes $94 \%$ and dominates the $\lambda_{\mathrm{m}}=440 \mathrm{~nm}$ emission band. When $\lambda_{\mathrm{m}}$ changes to $320 \mathrm{~nm}$, then the pedestal is preserved, but the contribution of the fast nanosecond component is reduced to $75 \%$.

\section{Discussion}

\subsection{Electronic structure parameters}

The usual way to obtain the electronic structure parameters from the VUVspectroscopy technique is the study of the reflection spectra followed by a dispersion analysis, or Kramers-Krönig transform. The reflection spectra of many ionic crystals in this regard are well studied, e.g. [26, 27]. Unfortunately, the grown LiAF polycrystalline samples do not have a form suitable for the study of the reflection spectra. In this regard, some electronic structure parameters could be derived solely from the results of the luminescent spectroscopy, Fig. 4, 7.

We are not aware of experimental data on optical absorption at the low-energy tail of the LiAF host absorption, but there are data available on related crystals. The values of low-temperature bandgap width for these crystals are: $E_{\mathrm{g}}=12.3 \mathrm{eV}$ for LiBAF [17]; $E_{\mathrm{g}}=12.65 \mathrm{eV}$ for $\mathrm{LiCAF}$ [12]; $E_{\mathrm{g}}=10.8 \mathrm{eV}$ for $\mathrm{AlF}_{3}$ [28]. The energy threshold for the excitation of anionic exciton in LiBAF is $E_{\mathrm{n}}=11.6 \mathrm{eV}$ [17]. In this context, the energy interval of $10.5-12.5 \mathrm{eV}$ is a reasonable estimate for the low-energy edge of the LiAF host absorption.

There is a narrow peak at $E_{\text {ex }}=11.8 \mathrm{eV}$ in the PLE-spectra of LiAF crystals at $T=7.2 \mathrm{~K}$ (Fig. 4), which not only falls within this energy range, but manifests all signs of an excitation peak of 'excitonic' luminescence. If this assumtion is correct, the profile of this peak at $11.8 \mathrm{eV}$ in PLE-spectra (Fig. 4) is caused by two competing processes. In the framework of simple diffusion concepts [29, 30], the low-energy slope of the PLE-peak is due to an increase in the optical absorption coefficient $\mu(E)$ in the range of several tens of $\mathrm{cm}^{-1}$, which occurs at the low-energy tail of the host absorption. High-energy slope of the PLE-peak 
corresponds to a further increase in $\mu(E)$ resulting in the surface energy losses. This leads to a decrease in PLE-efficiency in the energy range of $11.8-12.8 \mathrm{eV}$. The sharp increase in PLE-efficiency, in the energy range of $12.8-13.5 \mathrm{eV}$, should be attributed to interband transitions. From Fig. 4 it can be seen that the $E_{\mathrm{g}} \approx 12.5 \mathrm{eV}$ is quite reasonable estimate for the cut-off energy of PLE-spectrum at the Urbach tail. This interpretation of PLE-spectrum suggests that LiAF-crystal has a mobile electronic excitations - excitons. From theoretical concepts [29, 30] it follows that the excitonic absorption peak $\left(E_{\mathrm{n}}\right)$ should be localized in the energy range of $E_{\mathrm{ex}}<E_{\mathrm{n}}<E_{\mathrm{g}}$. This corresponds to a reasonable estimate: $11.8 \mathrm{eV}<E_{\mathrm{n}}<$ $12.5 \mathrm{eV}$.

\subsection{Excitonic luminescence}

In spite of the approximate nature of the electronic structure parameters derived in the previous section, they allow us to consistently interpret the experimental data on the luminescence of LiAF crystals.

PL emission band peaking at $320-350 \mathrm{~nm}$ is complex in origin. The longwavelength part of this band peaking at 340-350 nm (Fig. 3, curve 4), can most efficiently be excited at the low-energy tail of the host absorption at $E_{\mathrm{ex}}=11.8 \mathrm{eV}$. The most likely interpretation of the PL band at 340-350 nm is the following. We believe that the photoexcitation at the long-wavelength tail of the LiAF host absorption leads to the creation of unrelaxed excitons. The most probable decay channels for the excitons are: migration, followed by non-radiative decay; selftrapping, followed by radiative annihilation; and dissociation into an electron and a hole with the possible participation of the latter in the recombination process. Let us discuss the decay channels of unrelaxed excitons considering the experimental data.

Migration and non-radiative decay at the surface are responsible for the surface energy losses. PLE-spectra of LiAF, recorded at $T=7.2 \mathrm{~K}$ monitoring emission at 340-350 nm, have a well-resolved dominant peak in the excitonic energy region at $E_{\text {ex }}=11.8 \mathrm{eV}$, Fig. 4 . The presence of this narrow peak may indicate an excitonic mechanism of energy transfer in LiAF, which is typical for systems where luminescence is either excitonic in origin, or excitons are the intermediary in the energy transfer to emission centers. The excitonic origin of the spectral shape for the PLE peak at $E_{\text {ex }}=11.8 \mathrm{eV}$ has been discussed above.

The second channel of excitonic decay is a self-trapping and subsequent radiative annihilation of self-trapped exciton (STE). The results of this research work together with the published data on the various fluorides, e.g. [12, 17, 31], re-

vealed the characteristic features of the short-wavelength broadband luminescence 
in the crystals: among them, a fairly high quantum yield; a large Stokes shift; the absence of selective excitation bands in the optical transparency region; the presence of exponential component in the PL decay kinetics; efficient PL-excitation in the energy range of excitonic absorption; freezing of the efficient energy transfer to the lattice defects. It is known that such a set of properties exhibit STE in alkali halide crystals [32] or wideband low-symmetry oxides, for example, lithium borates [33]. This gives reason to believe that a broad PL emission band in LiAF crystals is due to radiative annihilation of relaxed electronic excitations - STE, whose decay causes luminescence at $340-350 \mathrm{~nm}$. The high efficiency of PL excitation at the low-energy tail of the host absorption indicates that the STE is produced by relaxation of unrelaxed exciton. The absence of 'freezing' of STE emission at low temperatures suggests a lack of self-trapping barrier or its low height, which is typical for many low-symmetry oxide with a complex host lattice.

PLE-spectra recorded at $T=7.2 \mathrm{~K}$ monitoring STE-emission (Figs. 4, $b ; 8$ ), demonstrate efficient excitation of the luminescence in the energy region above $E_{\mathrm{g}}$. This indicates that the STE excitation occurs in recombination processes. Self-trapped hole in alkali halide crystals is in the form of $V_{\mathrm{k}}$-center, which can act as the hole kernel of STE [32]. Therefore, one of the excitation channels for STE in these crystals is an electronic recombination at $V_{\mathrm{k}}$-centers. We are not aware of publications on $V_{\mathrm{k}}$-centers in LiAF crystals. However, there is convincing evidence of the existence of $V_{\mathrm{k}}$-centers and recombination processes with their participation in the related complex fluoride crystals [31], in particular $\mathrm{LiBaF}_{3}$ crystals. Self-trapping of holes in $\mathrm{LiBaF}_{3}$ crystals occurs in the form of fluorine $\mathrm{F}_{2}^{-}$, molecular $V_{\mathrm{k}}$-centers occupying the fluorine site and oriented along [110] direction [34]. The thermally stimulated migration of the $V_{\mathrm{k}}$-center occurs starting from $T=100 \mathrm{~K}$ via reorientation hops, without breaking the molecular bond; above $T=130 \mathrm{~K}$ the $V_{\mathrm{k}}$-center are thermally destroyed $[35,36]$.

\subsection{Defect luminescence}

PL emission band at $450 \mathrm{~nm}$ and short-wavelength part of the complex PL emission band with maximum at $320-325 \mathrm{~nm}$ can be excited in the energy range well-below $E_{\mathrm{n}}$, Fig. 3 (curves 1,2 ), so they should be attributed to the PL emission of defects. This explains the direct photoexcitation of these bands at $6.2-6.8 \mathrm{eV}$, Fig. 3. The presence of defects makes it possible to transfer of excitation energy to the emission centers through the migration of excitons. Alternatively, formation of near-defect excitons with subsequent relaxation and radiative decay in the vicinity of the defects may also occur. This explains the excitation of defect emission in 
PLE-energy range, where the creation of unrelaxed excitons occurs. The available experimental data do not allow us at this stage to discuss the origins of these defects in LiAF. However, related $\mathrm{LiBaF}_{3}$ crystal has been investigated in this regard and there are extensive data on lattice defects and recombination processes. Let's discuss them briefly.

Electronic F-type color centers in pure $\mathrm{LiBaF}_{3}$ have been studied by electron paramagnetic resonance (EPR) technique [37-39], optical spectroscopy [40-42], trap spectroscopy [43-45]. The luminescence bands at $300-370 \mathrm{~nm}$ in $\mathrm{LiBaF}_{3}$ was attributed to charge transfer transitions between F-type and $V_{\mathrm{k}}$ centers $[35,36]$.

The above results show that defect PL emission bands at 320-325 and $450 \mathrm{~nm}$ in LiAF have many properties in common with those of $\mathrm{LiBaF}_{3}$. We believe that further study of the origin of intrinsic lattice defects in LiAF (F-type and $V_{\mathrm{k}}$ centers) will allow us to explain the origin of the defect PL emission bands at $320-325$ and $450 \mathrm{~nm}$ similar to those for $\mathrm{LiBaF}_{3}$.

PL emission bands in the UV-VUV energy at 170 and $208 \mathrm{~nm}$ (Fig. 6) were registered upon the excitation at the optical transparency region of LiAF crystals (Fig. 7), so they are also caused by defect emission. The available experimental data do not allow us to give a final interpretation of their origin yet. At this stage, we can only make a reasonable assumption that the UV-VUV luminescence at 170 and $208 \mathrm{~nm}$ revealed for LiAF crystals at $300 \mathrm{~K}$ can be attributed to interconfigurational $5 \mathrm{~d}-4 \mathrm{f}$ radiative transitions in unintentionally introduced $\mathrm{Er}^{3+}$, or $\mathrm{Tm}^{3+}$ impurity ions. It is worth noting that in the related LiCAF crystals at $300 \mathrm{~K}$ exhibit luminescence in the spectral range of $160-210 \mathrm{~nm}$, due to $5 \mathrm{~d}-4 \mathrm{f}$ transitions in $\mathrm{Er}^{3+}$, or $\mathrm{Tm}^{3+}$ : the shortest- wavelength peak at $163-165 \mathrm{~nm}$ dominates PL emission spectrum, while other peaks in the spectral range of $180-210 \mathrm{~nm}$ are one order of magnitude lower in intensity [46]. This is quite consistent with our data for LiAF. Moreover, PLE-band at $8.7 \mathrm{eV}(\mathrm{FWHM}=0.6 \mathrm{eV})$ in LiAF crystals (Fig. 7) recorded monitoring emissions at 170 or $208 \mathrm{~nm}$, coincides with the wavelength $h v=140 \mathrm{~nm}(8.8 \mathrm{eV})$ used to excite $5 \mathrm{~d}-4 \mathrm{f}$ emission from $\mathrm{Er}^{3+}$ and $\mathrm{Tm}^{3+}$ in LiCAF [46] and certain other fluoride crystals [47, 48]. Relatively broadband luminescence at 163-165 $\mathrm{nm}$ in LiCAF had shortest wavelength among the fluoride crystal hosts ever reported at room temperature experiments. It is important that UV-VUV luminescence at $170 \mathrm{~nm}$, recorded for LiAF crystals at $300 \mathrm{~K}$, has substantially identical characteristics. This opens up the possibility of using VUV-luminescence of LiAF crystals in scintillators for radiation detectors, which employ photosensitive gases or photocathodes sensitive mostly to VUV photons. The unidentified impurity phase detected by XRD technique (see section 2.2) could be closely connected with the presence of these impurities. As 
the rare-earth ions $\mathrm{RE}^{3+}$ are substantially larger in size compared with equally charged host cations $\mathrm{Al}^{+}$, the unintentional doping could lead to the foreign phase formation as it was revealed for LiBAF in [16].

\section{Conclusions}

Thus, for the first time we have carried out a photoluminescence study for monoclinic LiAF crystals upon VUV- and XUV-excitations, using the low-temperature $(T=7.2 \mathrm{~K})$ time-resolved spectroscopy technique. The main conclusions are as follows.

Using Bridgman technique we have grown LiAF crystals suitable for optical studies. All the crystals were found $\beta$-LiAF with lattice parameters $a=14.2292(7)$; $b=8.4038(5) ; c=9.8800(5) \AA ; \beta=94.078(2)^{\circ}$. Low-temperature $(T=7.2 \mathrm{~K}) \mathrm{PL}$ emission spectra with time-resolution revealed the intrinsic PL emission band at 340-350 nm, which was ascribed to radiative annihilation of self-trapped excitons. Other bands at $\lambda_{\mathrm{m}}=320-325$ and $450 \mathrm{~nm}$ were attributed to luminescence caused by lattice defects. PLE-bands due to the creation of unrelaxed excitons were identified at $E_{\mathrm{ex}}=11.8 \mathrm{eV}$. PLE-spectra analysis gave estimates of the electronic structure parameters at $T=7.2 \mathrm{~K}$ : bandgap $E_{\mathrm{g}} \approx 12.5 \mathrm{eV}$, energy threshold for creation of unrelaxed excitons $11.8 \mathrm{eV}<E_{\mathrm{n}}<12.5 \mathrm{eV}$. We found efficient excitation of PL emission bands in the energy range of interband transitions $\left(E_{\mathrm{ex}}>13.5 \mathrm{eV}\right)$ and in the range of core transitions at $130 \mathrm{eV}$. In the PL spectra recorded at $300 \mathrm{~K}$ we have found extrinsic UV-VUV PL bands at 170 and $208 \mathrm{~nm}$. We expressed a reasonable assumption that these bands originate from interconfigurational $5 \mathrm{~d}-$ 4f radiative transitions in unintentionally introduced $\mathrm{Er}^{3+}$ or $\mathrm{Tm}^{3+}$ impurity ions. As far as we are aware, the UV-VUV emission in LiAF has shortest wavelength after LiCAF among the fluoride crystal hosts ever reported at room temperature experiments.

\section{Acknowledgments}

This work was partly supported by the Ministry of Education and Science of the Russian Federation (the basic part of the government mandate), HASYLAB DESY (Projects Nos. 20110843, 20080119EC), European Social Fund ("Mobilitas" program, MJD219), Estonian Research Council (Institutional Research Funding IUT02-26) and Baltic Science Link project coordinated by the Swedish Research Council, VR. 
[1] J. H. Burns, A. C. Tennissen, and G. D. Brunton, Acta Crystallogr. B 24 (2) (1968) 225-230.

[2] G. Garton and B. Wanklyn, J. Inorg. Nucl. Chem. 27 (11) (1965) 2466-2469.

[3] M. Hamadàne, J. Grannec, A. Guehria, and J. Ravez, Phase Transit. 73 (3) (2001) 423-437.

[4] A. K. Tyagi and J. R. Köhler, Mater. Res. Bull. 32 (12) (1997) 1683-1689.

[5] I. Koštenská, J. Vrbenská, and M. Malinovský, Chem. Zvesti 27 (3) (1973) 296-300.

[6] G. T. Furukawa, W. G. Saba, and J. C. Ford, J. Res. Nat. Bur. Stand. (US) 74A (5) (1970) 631-639.

[7] P. Fellner, S. Midtlyng, A. Sterten, and J. Thonstad, J. Appl. Electrochem. 23 (1) (1993) 78-81.

[8] R. Miyazaki and H. Maekawa, ECS Electrochem. Lett. 1 (6) (2012) A87A89.

[9] A. A. Merkulov, L. I. Isaenko, S. I. Lobanov, D. Y. Naumov, and N. V. Kuratieva, Acta Crystallogr. C64 (7) (2008) i66-i68.

[10] S. I. Omelkov, M. Kirm, E. Feldbach, V. A. Pustovarov, S. O. Cholakh, and L. I. Isaenko, J. Phys.: Condens. Matter. 22 (29) (2010) 295504(8).

[11] I. N. Ogorodnikov, S.I. Omelkov, V.A. Pustovarov, A. Kasikov, and M. Kirm, Opt. Mater. 39 (2015) 52-57.

[12] M. Kirm, M. True, S. Vielhauer, G. Zimmerer, N. V. Shiran, I. Shpinkov, D. Spassky, K. Shimamura, and N. Ichinose, Nucl. Instrum. Meth. Phys. Res. A 537 (2005) 291-294.

[13] C. D. Marshall, S. A. Payne, J. A. Spaeth, W. F. Krupke, G. J. Quarles, V. Castillo, and B. H. T. Chai, J. Opt. Soc. Am. B-Opt. Physics 11 (10) (1994) 2054-2065.

[14] N. Shiran, A. Gektin, S. Neicheva, M. Weber, S. Derenzo, M. Kirm, M. True, I. Shpinkov, D. Spassky, K. Shimamura, and N. Ichinose, Nucl. Instrum. Meth. Phys. Res. A 537 (2005) 266-270. 
[15] M. N. Sanz-Ortiz, F. Rodriguez, and R. Valiente, J. Phys.: Condens. Matter. $22(12)(2010) 125502$.

[16] S. I. Omelkov, V. Kiisk, I. Sildos, M. Kirm, V. Nagirnyi, V. A. Pustovarov, L. I. Isaenko, and S. I. Lobanov, Radiat. Meas. 56 (2013) 49-53.

[17] V. A. Pustovarov, I. N. Ogorodnikov, S.I. Omelkov, D. A. Spassky, and L. I. Isaenko, J. Opt. Soc. Am. B-Opt. Physics 31 (8) (2014) 1926-1934.

[18] M. H. Du and D. J. Singh, J. Appl. Phys. 112 (2012) 123516.

[19] M. H. Du and D. J. Singh, Proc. SPIE 8852 (2013) 885205.

[20] A. A. Mubarak and A. A. Mousa, Comp. Mater. Sci. 59 (2012) 6-13.

[21] M. J. Knitel, P. Dorenbos, J. T. M. De Haas, and C. W.E. van Eijk, $\mathrm{LiBaF}_{3}$, A scintillator for thermal-neutron detection with optimal $n$-gamma discrimination, in: Proceedings of the International Conference on Inorganic Scintillators and Their Applications (Delft University Press, Delft, 1995) 81-83.

[22] M. Kirm, A. Lushchik, Ch. Lushchik, S. Vielhauer, and G. Zimmerer, J. Lumin. 102-103 (2003) 307-312.

[23] G. Zimmerer, Radiat. Meas. 42 (4-5) (2007) 859-864.

[24] T. Balasubramanian, B. Jensen, S. Urpelainen, B. Sommarin, U. Johansson, M. Huttula, R. Sankar, E. Nõmmiste, S. Aksela, H. Aksela, and R. Nyholm, AIP Conf. Proc. 1234 (2010) 661-664.

[25] Bruker AXS, Karlsruhe, Germany, TOPAS: General profile and structure analysis software for powder diffraction data, v4.2 (2009).

[26] G. W. Rubloff, J. Freeouf, H. Fritzsche, and K. Murase, Phys. Rev. Lett. 27 (6) (1971) 1317-1320.

[27] G. W. Rubloff, Phys. Rev. B: Cond. Matter 5 (2) (1972) 662-684.

[28] D. König and G. Ebest, Solid-State Electronics 44 (1) (2000) 111-116.

[29] A. N. Vasil'ev and V. V. Mikhailin, Introduction in Solid State Spectroscopy, Moscow University Press, Moscow, 1987.

[30] A. Belsky and J. C. Krupa, Displays 19 (1999) 185-196. 
[31] J. H. Beaumont, W. Hayes, D. L. Kirk, and G. P. Summers, Proc. Roy. Soc. London. A. 315 (1520) (1970) 69-97.

[32] Ch. B. Lushchik, Free and self-trapped excitons in alkali halides: Spectra and dynamics, in: E. Rashba, M. Sturge (Eds.), Excitons, Publ. Conf., NorthHolland, (1982) 506-541.

[33] I. N. Ogorodnikov, V. A. Pustovarov, A. V. Kruzhalov, L. I. Isaenko, M. Kirm, and G. Zimmerer, Phys. Solid State 42 (3) (2000) 464-472.

[34] K. Somaiah, M. V. Narayana, and L. H. Brixner, Mater. Chem. Phys. 24 (4) (1990) 353-562.

[35] I. Tale, H.-J. Fitting, P. Kulis, V. Ogorodnik, U. Rogulis, M. Springis, V. Tale, J. Trokšs, and Ā. Veispāls, Radiat. Eff. Defect. Solid. 149 (1-4) (1999) 269272.

[36] I. Tale, M. Springis, U. Rogulis, V. Ogorodnik, P. Kulis, V. Tale, A. Veispals, and H. J. Fitting, Radiat. Meas. 33 (5) (2001) 751-754.

[37] A. Fedotovs, E. Elsts, U. Rogulis, A. Gulans, I. Tale, M. Nikl, N. Ichinose, and K. Shimamura, Phys. Status Solidi (c) 4 (3) (2007) 1284-1287.

[38] U. Rogulis, V. Ogorodnik, I. Tale, and A. Veispals, Radiat. Eff. Defect. Solid. 157 (6-12) (2002) 699-703.

[39] U. Rogulis, J.-M. Spaeth, I. Tale, M. Nikl, N. Ichinose, and K. Shimamura, Radiat. Meas. 38 (4-6) (2004) 663-666.

[40] P. Kulis, I. Tale, M. Springis, U. Rogulis, J. Trokss, A. Veispals, and H.J. Fitting, Radiat. Eff. Defect. Solid. 149 (1-4) (1999) 97-100.

[41] P. Kulis, I. Tale, M. Springis, U. Rogulis, A. Veispals, and H.-J. Fitting, Radiat. Eff. Defect. Solid. 155 (1-4) (2001) 77-81.

[42] P. Kulis, M. Springis, and I. Tale, Radiat. Eff. Defect. Solid. 157 (6-12) (2002) 737-741.

[43] P. Kulis, I. Tale, and G. Rudlof, Radiat. Protect. Dosimetry 100 (1-4) (2002) $167-170$. 
[44] P. Kulis, I. Tale, I. Gromuls, M. Nikl, N. Ichinose, and K. Shimamura, Radiat. Meas. 38 (4-6) (2004) 723-726.

[45] I. Tale, P. Kulis, U. Rogulis, V. Tale, J. Trokss, A. Veispals, M. BarbozaFlores, and H.-J. Fitting, J. Lumin. 72-74 (1997) 722-723.

[46] A. Yoshikawa, T. Yanagida, Y. Yokota, A. Yamaji, Y. Fujimoto, J. Pejchal, V. I. Chani, N. Kawaguchi, S. Ishizu, K. Fukuda, T. Suyama, and M. Nik1, Opt. Mater. 32 (9) (2010) 845-849.

[47] J. Becker, J. Y. Gesland, N. Yu. Kirikova, J.C. Krupa, V. N. Makhov, M. Runne, M. Queffelec, T.V. Uvarova, and G. Zimmerer, J. Lumin. 78 (1998) 91-96.

[48] J. Becker, J. Y. Gesland, N. Yu. Kirikova, J.C. Krupa, V. N. Makhov, M. Runne, M. Queffelec, T.V. Uvarova, and G. Zimmerer, J. Alloys Compd. 275-277 (1998) 205-208.

[49] L. B. McCusker, R. B. von Dreele, D. E. Cox, D. Louër, and P. Scardi, J. Appl. Cryst. 32 (1999) 36-50. 
Table 1: Most relevant parameters of processing and refinement for LiAF.

\begin{tabular}{lc}
\hline Parameter & Value \\
\hline Compound & $\mathrm{Li}_{3} \mathrm{AlF}_{6}$ \\
Molar mass, g/mol & 161.7950 \\
Symmetry group & $C 2 / c$ \\
$a, \AA$ & $14.2292(7)$ \\
$b, \AA$ & $8.4038(5)$ \\
$c, \AA$ & $9.8800(5)$ \\
$\beta$, grad & $94.078(2)$ \\
$V, \AA$ & $1178.45(11)$ \\
$Z$ & 4 \\
$2 \Theta-i n t e r v a l$, grad & $5-110$ \\
Number of reflections & 750 \\
Number of refined parameters & 95 \\
$R_{\text {wp }}, \%$ & 10.58 \\
$R_{\mathrm{p}}, \%$ & 7.76 \\
$R_{\text {exp }}, \%$ & 8.00 \\
$\chi^{2}$ & 1.32 \\
$R_{\mathrm{B}}, \%$ & 1.98
\end{tabular}

Note. The agreement indices ( $R$ values) were defined in agreement with Ref. [49]: $R_{\mathrm{wp}}$ is the weighted-profile $R$-value; $R_{\mathrm{p}}$ is $R$-pattern; $R_{\exp }$ is the statistically expected $R$-value; $R_{\mathrm{B}}$ is the Bragg-intensity $R$-value; $\chi=R_{\mathrm{wp}} / R_{\text {exp }}$ is the goodness of fit. 
Table 2: Fractional atomic coordinates $(\mathrm{x}, \mathrm{y}, \mathrm{z})$ and isotropic displacement $\left(B_{\text {iso }}\right)(\AA)$ for LiAF.

\begin{tabular}{lcccc}
\hline Atom & $\mathrm{x}$ & $\mathrm{y}$ & $\mathrm{z}$ & $B_{\text {iso }}$ \\
\hline Li1 & 0 & $0.164(6)$ & 0.25 & $3.0(12)$ \\
Li2 & $0.298(2)$ & $0.338(4)$ & $0.589(3)$ & $1.0(6)$ \\
Li3 & $0.315(2)$ & $0.205(3)$ & $0.922(3)$ & $1.7(6)$ \\
Li4 & $0.0473(19)$ & $0.337(4)$ & $0.531(3)$ & $2.1(7)$ \\
Li5 & $0.1488(17)$ & $0.857(3)$ & $0.266(3)$ & $1.0(6)$ \\
Al1 & 0 & 0 & 0 & $1.33(19)$ \\
A12 & $0.3366(4)$ & $0.0091(11)$ & $0.7004(4)$ & $1.27(14)$ \\
F1 & $0.0952(6)$ & $0.3431(14)$ & $0.1995(9)$ & $2.00(12)$ \\
F2 & $0.2297(5)$ & $0.3477(13)$ & $0.8815(8)$ & $2.00(12)$ \\
F3 & $0.1033(6)$ & $0.3419(13)$ & $0.6989(9)$ & $2.00(12)$ \\
F4 & $0.2512(5)$ & $0.0154(12)$ & $0.8280(7)$ & $2.00(12)$ \\
F5 & $0.0778(6)$ & $0.1548(11)$ & $0.9403(8)$ & $2.00(12)$ \\
F6 & $0.9361(6)$ & $0.1637(11)$ & $0.0595(9)$ & $2.00(12)$ \\
F7 & $0.4220(5)$ & $0.9777(10)$ & $0.5687(8)$ & $2.00(12)$ \\
F8 & $0.2637(6)$ & $0.1505(13)$ & $0.6039(8)$ & $2.00(12)$ \\
F9 & $0.0706(5)$ & $0.0086(14)$ & $0.1588(6)$ & $2.00(12)$ \\
\hline
\end{tabular}


Table 3: Lengths of the principal bonds ( $₫$ ) for LiAF.

\begin{tabular}{lc|lc}
\hline Bond & Length & Bond & Length \\
\hline Li1-F1 & $2.11(4)$ & Li4-F7 & $1.91(3)$ \\
Li1-F6 & $2.032(9)$ & Li4-F7 & $2.19(3)$ \\
Li1-F9 & $1.91(3)$ & Li5-F2 & $2.32(3)$ \\
Li2-F4 & $1.87(3)$ & Li5-F3 & $1.89(3)$ \\
Li2-F6 & $2.01(3)$ & Li5-F4 & $1.88(3)$ \\
Li2-F8 & $1.66(3)$ & Li5-F5 & $2.06(3)$ \\
Li2-F8 & $2.04(3)$ & Li5-F8 & $2.37(3)$ \\
Li3-Li & $2.60(4)$ & Li5-F9 & $1.96(3)$ \\
Li3-F1 & $1.86(3)$ & A11-F5 & $1.833(9)$ \\
Li3-F2 & $1.73(3)$ & A11-F6 & $1.772(9)$ \\
Li3-F2 & $2.13(3)$ & A11-F9 & $1.804(6)$ \\
Li3-F4 & $2.02(3)$ & A12-F1 & $1.824(12)$ \\
Li3-F5 & $2.30(3)$ & A12-F2 & $1.810(12)$ \\
Li3-F7 & $2.55(3)$ & A12-F3 & $1.891(12)$ \\
Li4-F3 & $1.79(3)$ & A12-F4 & $1.812(8)$ \\
Li4-F5 & $2.38(3)$ & A12-F7 & $1.862(8)$ \\
Li4-F6 & $1.74(3)$ & A12-F8 & $1.805(12)$ \\
\hline
\end{tabular}




\section{List of Figure Captions}

Figure 1. Rietveld difference plot for LiAF crystal at $T=300 \mathrm{~K}$.

Figure 2. Crystal structure of LiAF.

Figure 3. PL emission spectra of LiAF crystals recorded at $T=7.2 \mathrm{~K}$ using CCD-camera upon VUV-excitation at different energies $E_{\text {ex }}$.

Figure 4. PL excitation spectra of LiAF crystals recorded at $T=7.2 \mathrm{~K}$ monitoring emission at $\lambda_{\mathrm{m}}=440(a)$ and $340 \mathrm{~nm}(b)$ in time-integrated mode TI (1), and within time-windows $\mathrm{TW}_{1}(2)$, and $\mathrm{TW}_{2}(3)$. Each curve is normalized to unity at the maximum of intensity.

Figure 5. PL decay kinetics of LiAF crystals recorded at $T=7.2 \mathrm{~K}$ monitoring emission at $\lambda_{\mathrm{m}}=440(a)$ and $340 \mathrm{~nm}(b)$ upon VUV excitation at different energies $E_{\text {ex }}$.

Figure 6. Time-resolved PL emission spectra of LiAF crystals recorded at $T=300 \mathrm{~K}$ monitoring emission within time-window 1-6 ns using SR-excitation pulses with the $10 \mathrm{~ns}$ repetition period.

Figure 7. PLE spectra of LiAF crystals recorded at $T=300 \mathrm{~K}$ monitoring emission at $\lambda_{\mathrm{m}}=170$ and $208 \mathrm{~nm}$ within time-window of $1-6 \mathrm{~ns}$. Curve $(1)$ is normalized to unity at the maximum of intensity, whereas curve (2) is normalized arbitrary for better viewing.

Figure 8. Time-resolved PL emission spectra of LiAF crystals recorded at $T=300 \mathrm{~K}$ monitoring emissions in time-integrated mode TI, and within timewindows $\mathrm{TW}_{1}(2)$, and $\mathrm{TW}_{2}$ upon excitation at $E_{\mathrm{ex}}=130 \mathrm{eV}$. Experimental points are connected by straight line segments for better viewing. Each curve is normalized to unity at the maximum of intensity.

Figure 9. PL decay kinetics of LiAF crystals recorded at $T=300 \mathrm{~K}$ monitoring emission at $\lambda_{\mathrm{m}}=440$ and $320 \mathrm{~nm}$ upon XUV excitation at $E_{\mathrm{ex}}=130 \mathrm{eV}$. 


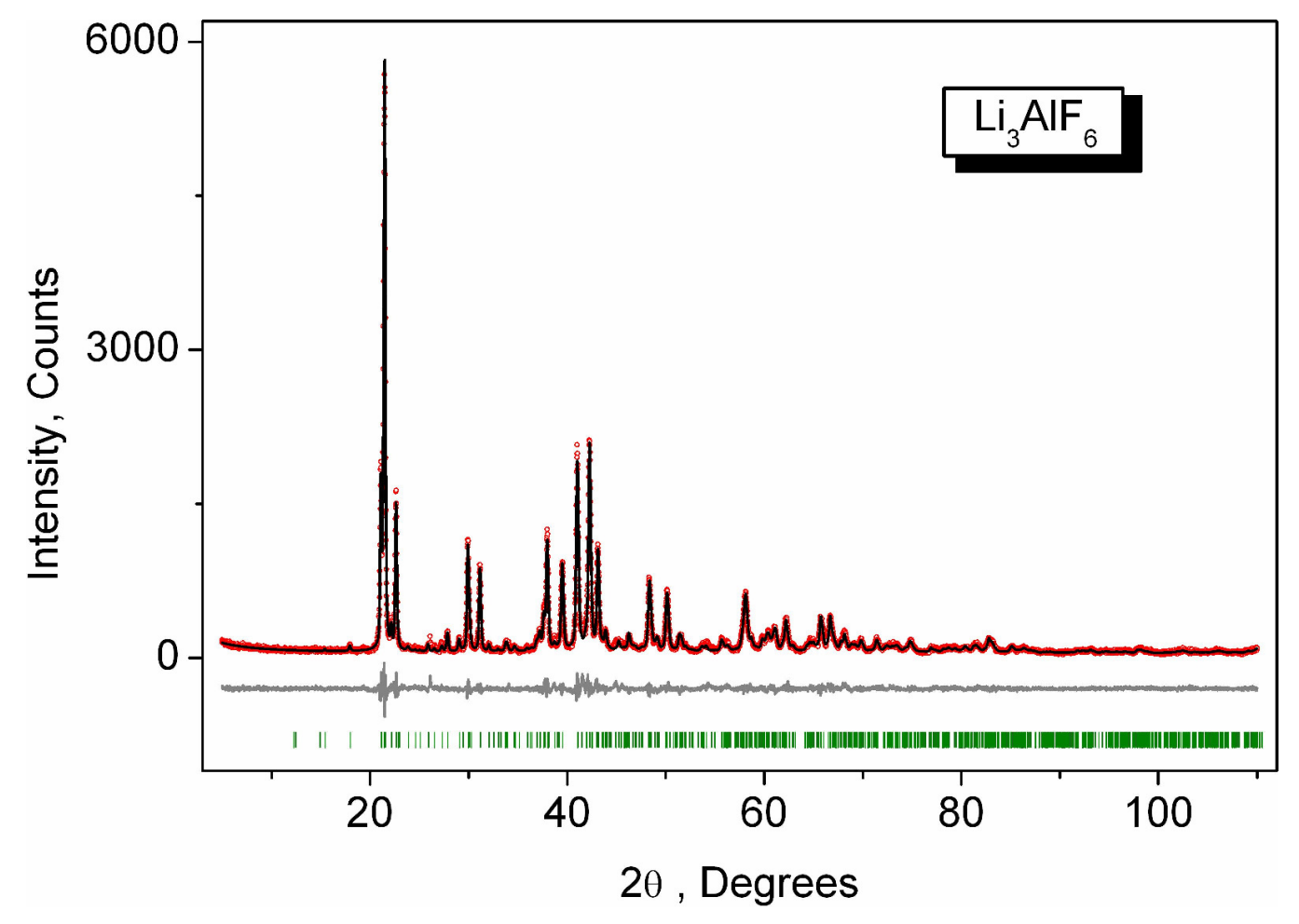

Figure 1: Rietveld difference plot for LiAF crystal at $T=300 \mathrm{~K}$. 


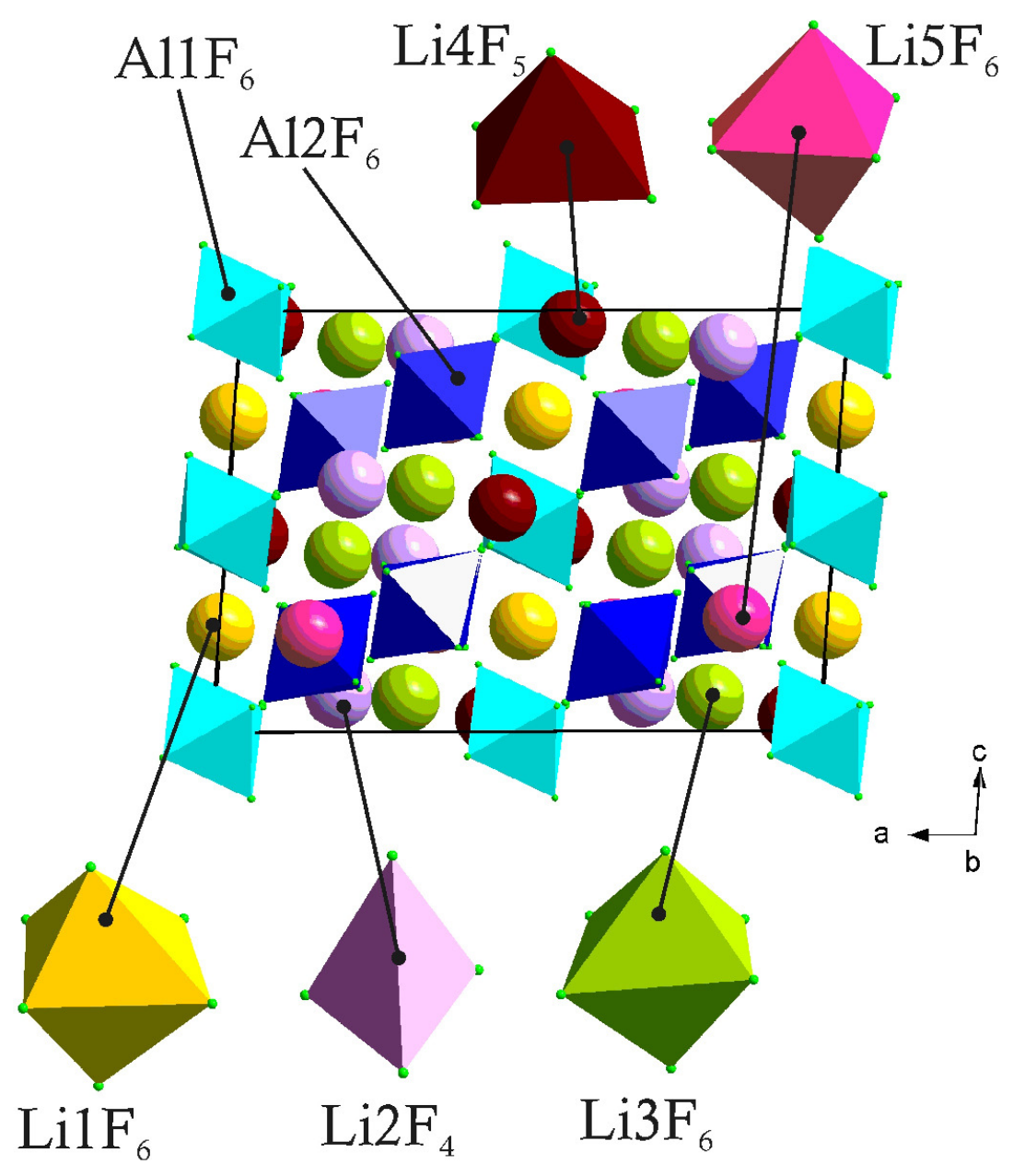

Figure 2: Crystal structure of LiAF. 


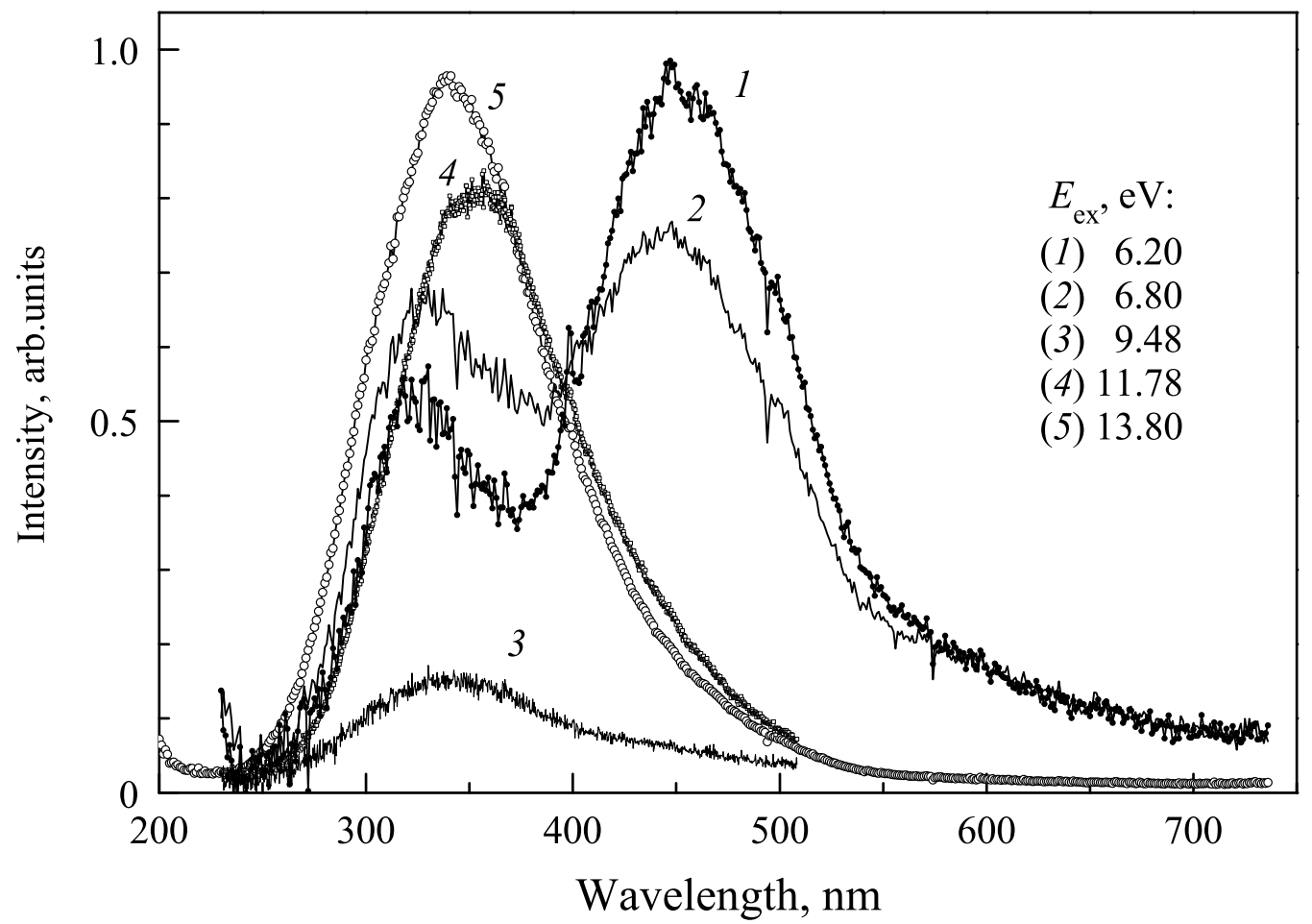

Figure 3: PL emission spectra of LiAF crystals recorded at $T=7.2 \mathrm{~K}$ using CCD-camera upon VUV-excitation at different energies $E_{\mathrm{ex}}$. 


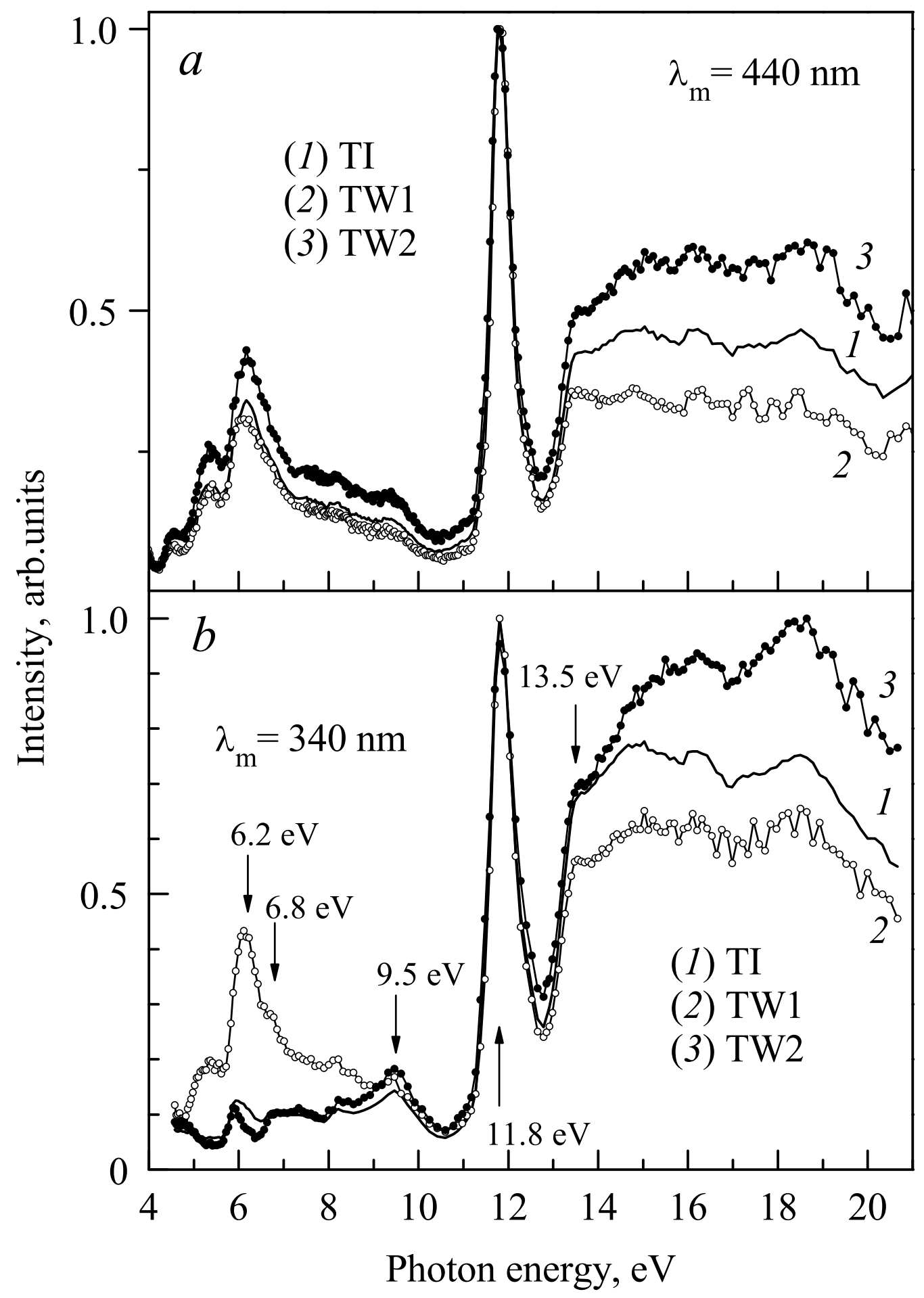

Figure 4: PL excitation spectra of LiAF crystals recorded at $T=7.2 \mathrm{~K}$ monitoring emission at $\lambda_{\mathrm{m}}=440(a)$ and $340 \mathrm{~nm}(b)$ in time-integrated mode TI (1), and within time-windows $\mathrm{TW}_{1}(2)$, and $\mathrm{TW}_{2}$ (3). Each curve is normalized to unity at the maximum of intensity. 


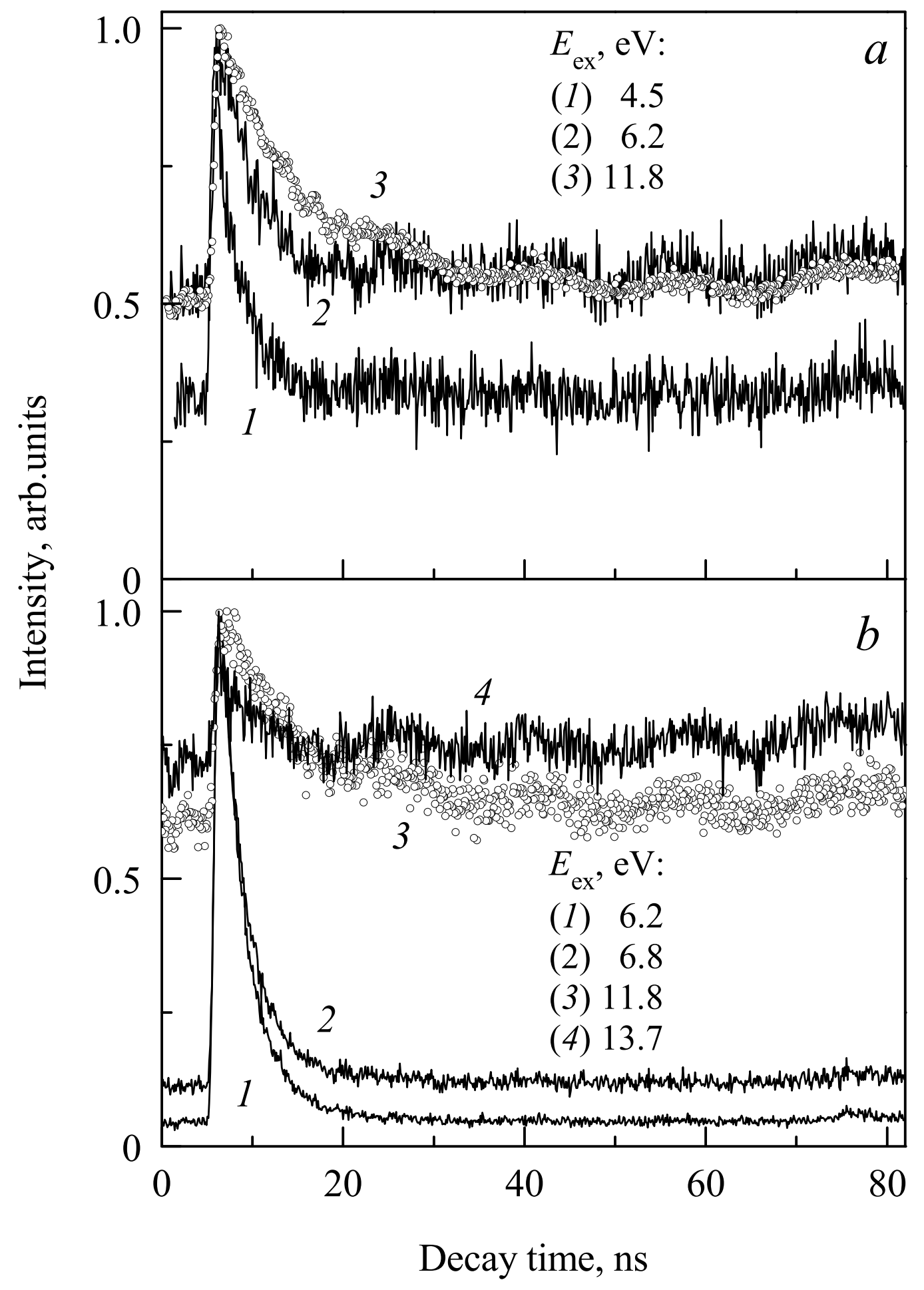

Figure 5: PL decay kinetics of LiAF crystals recorded at $T=7.2 \mathrm{~K}$ monitoring emission at $\lambda_{\mathrm{m}}=440$ (a) and $340 \mathrm{~nm}(b)$ upon VUV excitation at different energies $E_{\mathrm{ex}}$. 


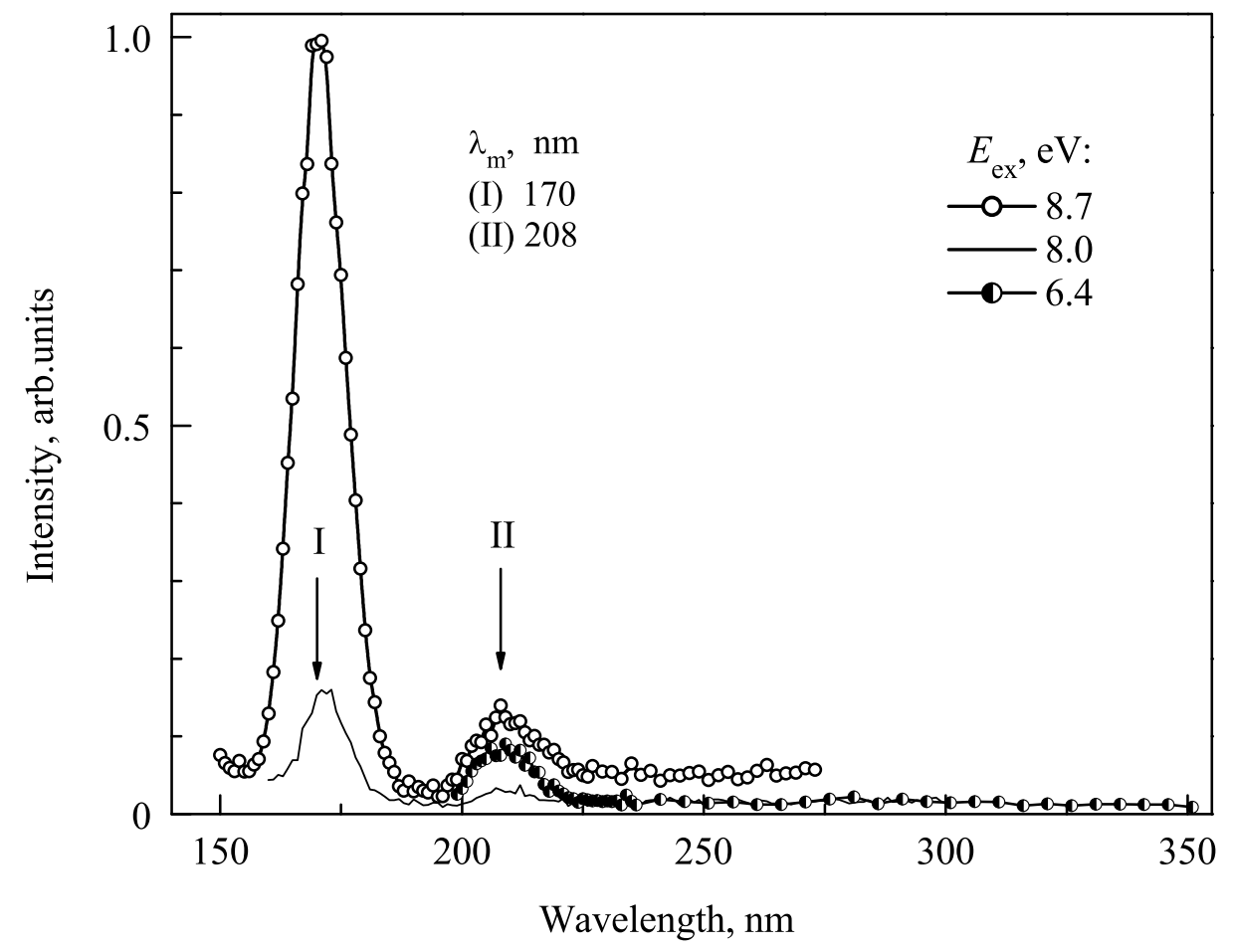

Figure 6: Time-resolved PL emission spectra of LiAF crystals recorded at $T=300 \mathrm{~K}$ monitoring emission within time-window of 1-6 ns using SR-excitation pulses with the $10 \mathrm{~ns}$ repetition period. 


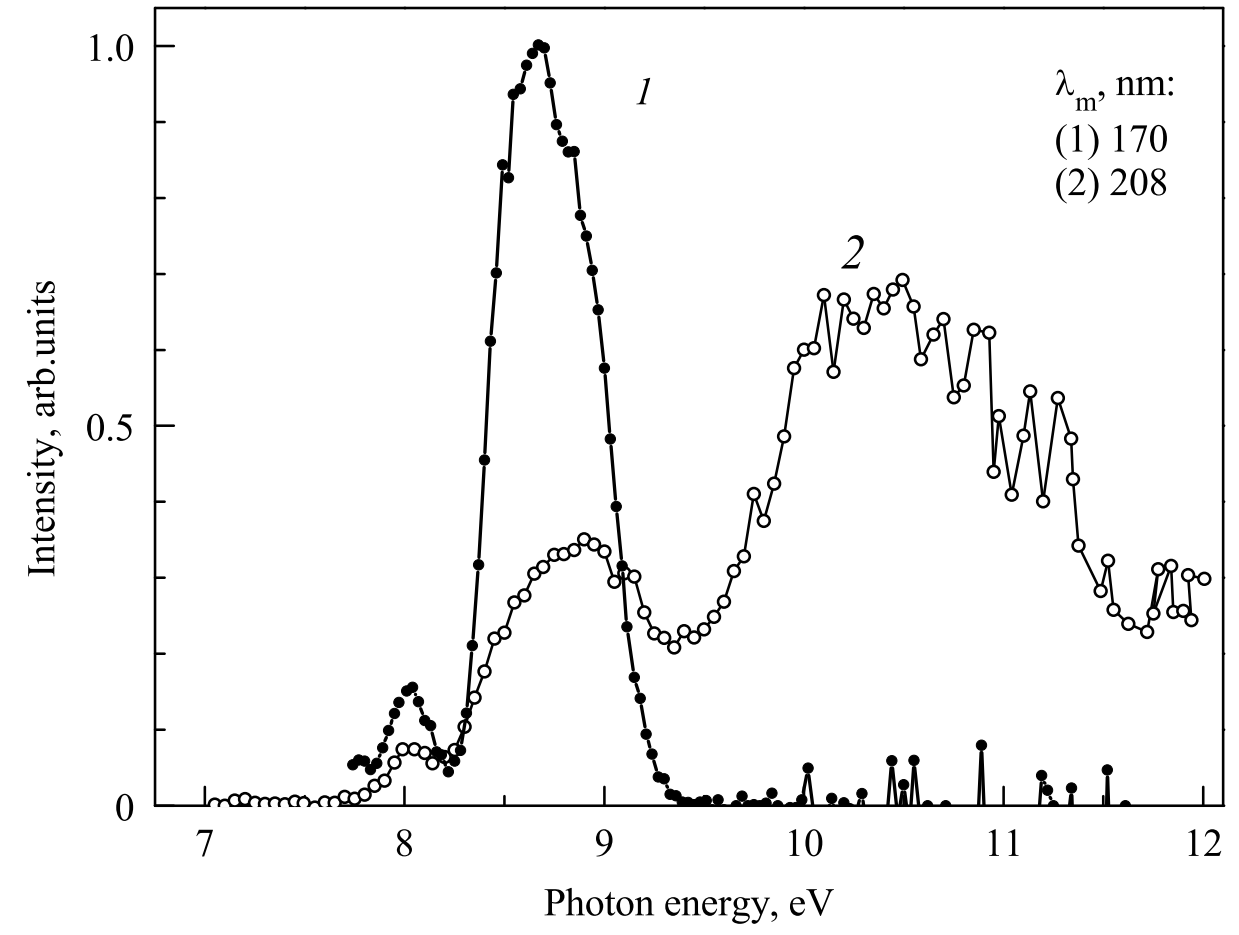

Figure 7: PLE spectra of LiAF crystals recorded at $T=300 \mathrm{~K}$ monitoring emission at $\lambda_{\mathrm{m}}=170$ and $208 \mathrm{~nm}$ within time-window 1-6 ns. Curve (1) is normalized to unity at the maximum of intensity, whereas curve (2) is normalized arbitrary for better viewing. 


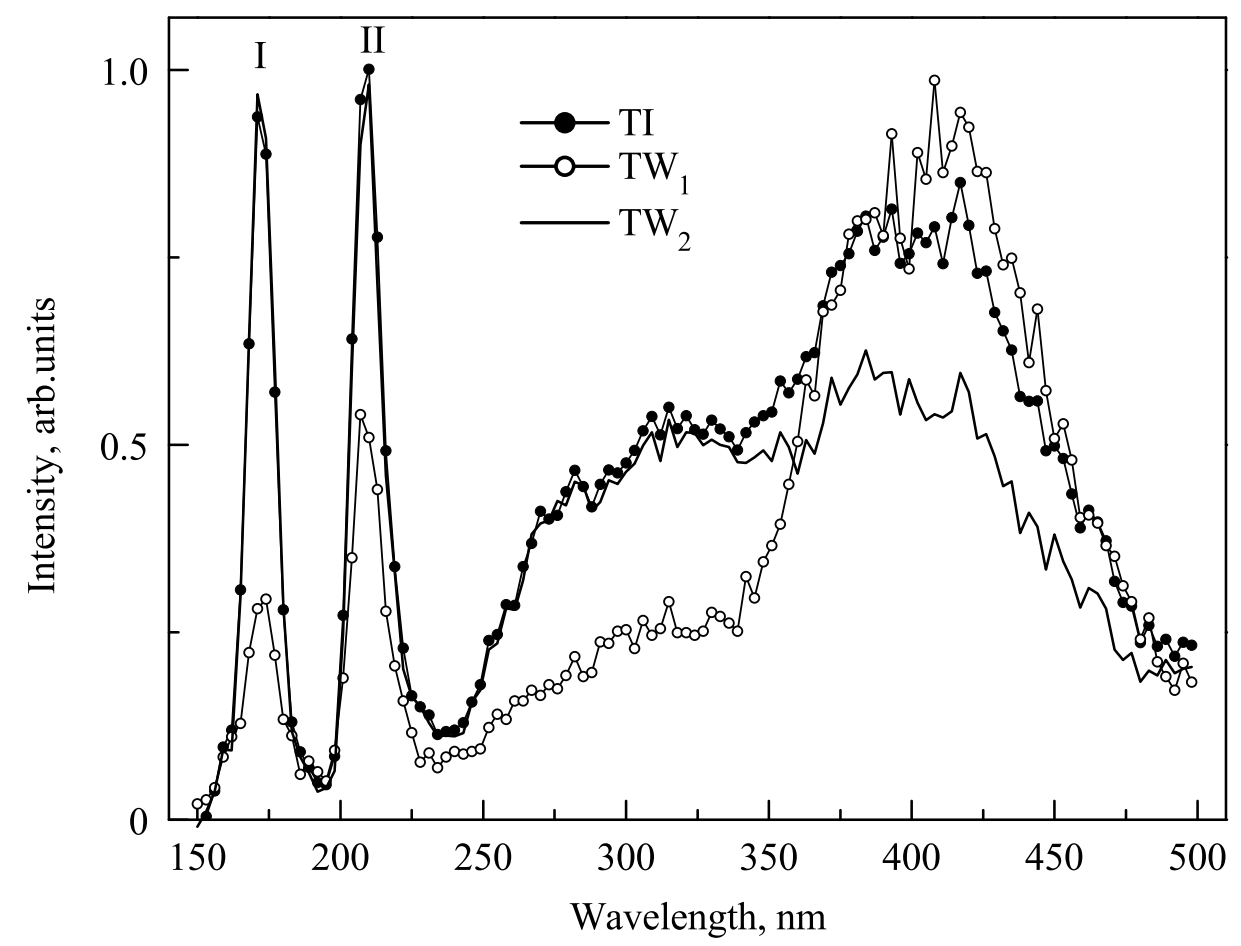

Figure 8: Time-resolved PL emission spectra of LiAF crystals recorded at $T=300 \mathrm{~K}$ monitoring emissions in time-integrated mode TI, and within time-windows $\mathrm{TW}_{1}(2)$, and $\mathrm{TW}_{2}$ upon excitation at $E_{\mathrm{ex}}=130 \mathrm{eV}$. Experimental points are connected by straight line segments for better viewing. Each curve is normalized to unity at the maximum of intensity. 


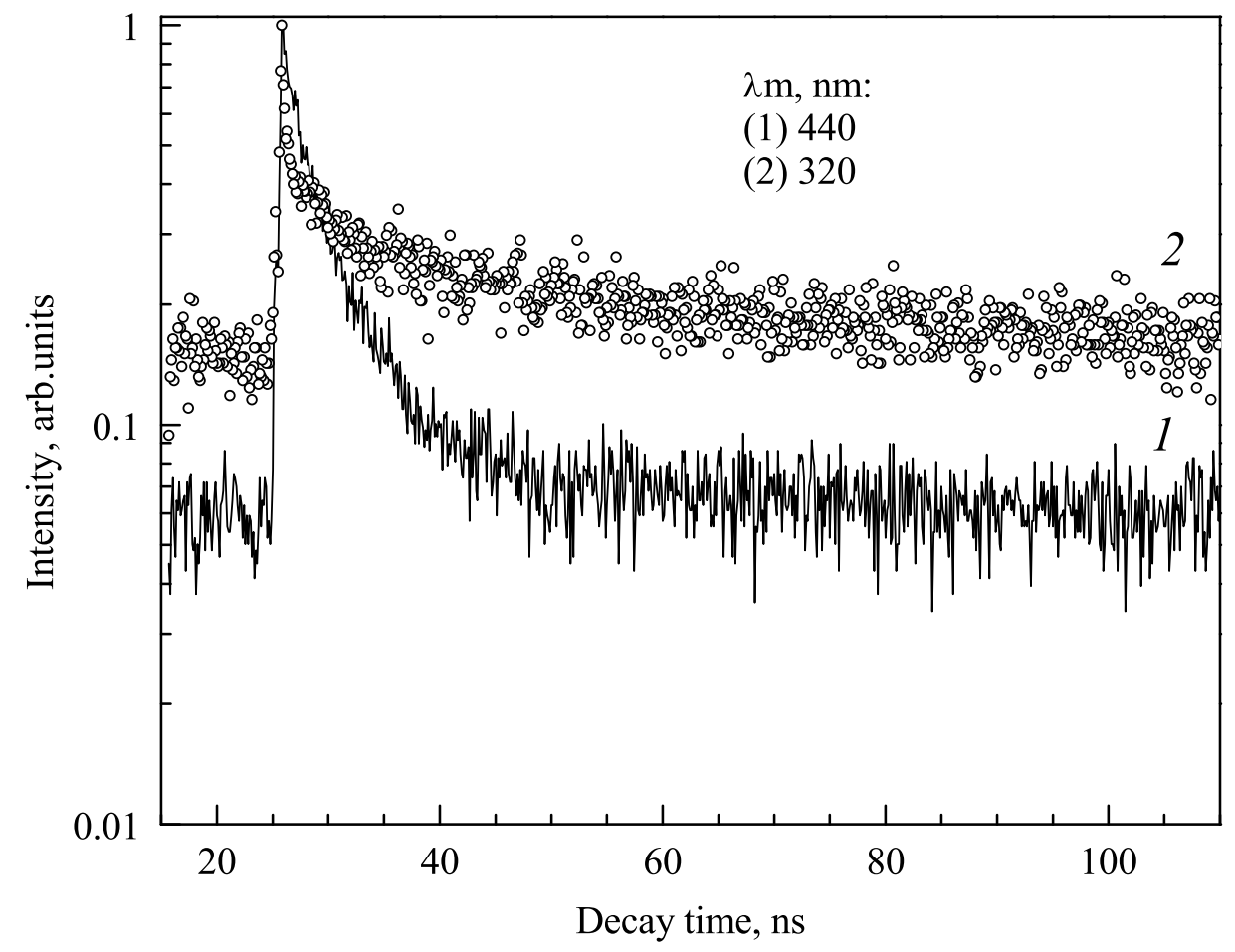

Figure 9: PL decay kinetics of LiAF crystals recorded at $T=300 \mathrm{~K}$ monitoring emission at $\lambda_{\mathrm{m}}=440$ and $320 \mathrm{~nm}$ upon XUV excitation at $E_{\mathrm{ex}}=130 \mathrm{eV}$. 